\title{
Australian mothering in cross-national perspective: time allocation, gender gaps, scheduling, and subjective time pressure
}

\author{
Lyn Craig*, Judith Brown and Theun Pieter van Tienoven
}

**lyn.craig@unimelb.edu.au ORCID: 0000-0001-9723-7255

Peer-reviewed pre-copyedited version of chapter published as Craig, Lyn, Judith Brown and Theun Pieter van Tienoven 2019 as 'Australian mothering in cross-national perspective: time allocation, gender gaps, scheduling, and subjective time pressure', in Australian Mothering: Historical and Sociological Perspectives. Editors: Leahy C, Bueskens P. 1, 317-336. Palgrave Macmillan, Switzerland. Publishers version 10.1007/978-3-030-20267-5_15

\section{Introduction}

Motherhood brings significant change to the way women spend and experience their time. Having children is an intensely personal experience, yet much of the practical impact upon parents' time is shaped by the political economy, and the social organization of work and care, of the time and place in which they live. In some national contexts, including Australia, social and economic policies frame managing work and family as a private issue, to be organized within households, or paid for through market arrangements. Others provide extensive public supports for work-family reconciliation, which lessen the direct time burden upon mothers and facilitate more-equal gender divisions of paid work and unpaid housework and care. What implications do these contrasting approaches have for mothers' daily lives and how the time impacts of children in Australia compare internationally? To explore how Australia compares with other countries in time-related aspects of parenting, this chapter uses nationally-representative time diary data from Australia, Korea, Spain and Finland $(n=24,449)$. It examines mothers and fathers' time in paid work, housework and childcare, leisure and sleep; gender divisions of work and care as children grow; when work, care leisure and sleep are scheduled over the day, and the subjective time pressure associated with transitions to parenthood.

\section{Background}

As work and family demands have escalated over recent decades, time scarcity has become a pervasive feature of contemporary life (Jacobs and Gerson 2004). Central to the issue is the growing work force participation of women, which has added to family workloads (Bianchi, Robinson, and Milkie 2006, Jacobs and Gerson 2004, Strazdins et al. 2011, Sullivan 2014). Mothers' and fathers' child caregiving time has also gone up (Buddelmeyer, Hamermesh, and Wooden 2017, Sayer 2016), meaning that both work and family time demands have grown.

Parenthood increases both time demands (more to do) and scheduling constraints (when it must be done). This creates time stress, which can be both objective, in having too much to do, and subjective, in feeling constantly rushed and harried, unable to manage all the demands. Time stress can be exacerbated by having to meet deadlines, and by having to juggle incompatible role demands, such as paid work and family care. The issue is important 
because time stress adversely affects wellbeing, and threatens mental health (Kleiner 2014, Strazdins et al 2011). It is a key aspect of parental welfare (Rose, Hewitt, and Baxter 2013) which contributes to differences in subjective wellbeing between parents and nonparents, with research suggesting these differences are wider for women than men (Buddelmeyer et al 2017; Strazdins et al 2011).

It is well known that men and women respond to the demands of parenthood differently, with women doing most domestic work and care and men devoting longer hours to employment (for overviews see Bianchi and Milkie 2010, Monna and Gauthier 2008). However, patterns in how motherhood and fatherhood relate to both objective time allocation and subjective time stress likely differ cross-nationally, because the pressures associated with having and raising children do not occur in a social vacuum. Paying attention to the context in which parenting occurs can identify conditions that make the consequences of parenthood more gender-equal. For example, subsidized childcare and paid parental leaves facilitate women's workforce participation (Lewis 2009) and mean that economic motherhood penalties are wider in some countries than others (Budig and England 2001, Budig, Misra, and Boeckmann 2012, Waldfogel 1998). There is reason to expect that the stress of having children, including subjective time pressure gaps between parents and nonparents, and between mothers and fathers, are similarly variable, because the objective time demands of parenthood vary. For example, time use studies find larger differences between the total market and nonmarket labor of couples with children and couples without children in Anglo than in Northern European countries (Craig and Mullan 2010) and that the impact of parenthood on the gender division of labor is not pronounced in Sweden (Dribe and Stanfors 2009) but is in Australia and the USA (Yavorsky, Kamp Dush, and Schoppe-Sullivan 2015).

The aim of this chapter is to explore how Australia compares with other countries in timerelated aspects of mothering. It uses time use data from Australia, Korea, Spain and Finland to investigate how time allocation, daily scheduling and subjective time stress differ by parenthood and age of youngest child for men and women in each country. Table 1 summarizes some of the multiple institutional features likely to influence the time impacts of children, and how they fall by gender.

[Table 1 about here]

As shown in Table 1, there are some overlaps and some convergence in contextual factors. Australia has high rates of female part time work, and average fulltime work hours (usually worked by men) are long (Craig and Mullan 2010). Early Childhood Education and Care (ECEC) attendance is low, reflecting intensive mother care, whilst social attitudes to gender are relatively liberal. Korea also has long male work hours. In that country, attitudes about gender and parenting are conservative, but there is high attendance in ECEC and most children attend after-school tutoring, which may lower parental time demands. Spain has high male unemployment, but long working hours for those who are employed, and fairly conservative gender attitudes. Of the four countries, Finland is most supportive of women's work. It has shorter average fulltime work hours than elsewhere, which promotes gender equity in market work time (Craig, Churchill and Wong, 2018). Child-raising is seen as collective social responsibility, and there is an active discourse on father involvement, and gender equality is an identified policy goal (Lewis 2009; Gornick and Meyers 2003). Overall, the institutional features and social indicators shown in Table1 suggest that of the four countries, Finland is the most progressive in promoting gender equality, Korea is the least progressive, and Australia and Spain fall between. 
To compare the subjective and objective time demands of parenthood across these contexts, we first establish average national patterns in five types of time use - leisure, sleep, paid work, housework and care, and investigate associations between gender, parenthood and time spent in each. Paid work, housework and childcare, which are productive and effortful activities, increase time pressure (Hamermesh and Lee 2007, Kleiner 2014, Mattingly and Sayer 2006), while recuperative activities such as leisure and sleep are likely to ameliorate it (Hurst 2008, Plage, Perales, and Baxter 2016). Thus, all five activities are important to understanding objective time pressure. We investigate how the time impacts of parenthood relate to children's age, and look at scheduling constraints, examining how work and care is timed over the course of the day, for men and for women. Finally, we identify within-country associations between parenthood, age of youngest child, and being subjectively time stressed, and whether associations differ significantly for men and women within countries.

\section{Data and Method}

\section{Data}

We use nationally representative Time Use Surveys (TUS) of Australia (2006), Spain (2009), Korea (2009) and Finland (2009) conducted by the national statistical agency of each country. All collected information through a self-completed time diary covering 24 hours of each sampled day. We drew a sample of twenty- to-fifty-four-year-old men and women with and without children up to 14 years of age from couple households, consisting of 11,695 men's and 12,754 women's diaries. (Australia $=2142$ male, 2459 female, Korea $=5974$ male, 6322 female, Spain = 2420 male, 2666 female, Finland = 1159 male, 1307 female) .

\section{Dependent variables}

To capture objective time pressure, we calculated daily time spent in market work, housework (including domestic purchasing), childcare, leisure/socializing and sleep. Subjective time stress was measured through a survey question in each of the countries except Spain. We dichotomize responses into a binary outcome variable that contrasts those who "always/all the time" or "often" feel time stressed with those who "sometimes/from time to time", "rarely/not really" or "never/hardly ever" do so. Spain had no indicator of subjective time stress, we exclude it from these analyses. We use the terms "subjective time pressure" and "feeling rushed or pressed for time" interchangeably.

\section{Analysis plan and independent variables}

We first describe average recuperative and productive activities in each country. For crossnational comparisons of time spent in each activity, we pool the country samples and run linear regressions stratified by gender. The key independent variables are country (Australia (omitted)/Korea/Spain/Finland), parenthood, and interactions between them. We captured parenthood by a series of dummy variables: no children (omitted), age of the youngest child is $0-4$ years, 5-9 years, or 10-14 years, to see how the time effects change as children grow, and to examine cross-national variation, we included interaction terms for age of youngest child by country. In the text we show graphs with fitted values from the regression analyses, highlighting the differences between fathers and mothers in each country in both time allocation, and in how the activities are scheduled over an average weekday.

To investigate subjective time stress, we used logistic regression modelling. Logistic regression analyses show how each independent variable is associated with the probability 
(odds) of a given outcome. In this case, our key independent variables are those capturing parenthood: no children (omitted), age of the youngest child is 0-4 years, 5-9 years, or 10-14 years, and the outcome is the odds of men and women experiencing subjective time stress. We stratify by gender and country. Post-regression Wald tests determine whether associations between parenthood and odds of being time stressed differ significantly by gender within Australia, Korea and Finland (recall that Spain did not measure subjective time stress).

Control variables: In all regression models, we enter respondent's age in years. We include education (has a college degree yes/no) as a dummy indicator of earning capacity and we include jobs status (not employed (omitted)/non-professional/ professional status). The models are deliberately parsimonious to exclude factors which may be confounded with the outcome variables and/or parenthood status. Also, we were unable to include some potential variables of interest, including disability of child or parent, sexuality or cultural background, because they were not consistently available across the four time use surveys. Our sample therefore would have included these demographic variations, but we could not isolate out whether and how they impact objective and subjective time pressure. Table 2 describes the sample and delineates country and gender differences in the dependent and independent variables.

[Table 2 about here]

\section{Results}

Figure 1 shows variations in average time use by gender and country. Paid and unpaid work activities that add to time pressure are above the zero line; leisure/socializing and sleep, recuperative activities likely to mitigate time pressure, are below the zero line. Men report more time in paid work and leisure and less time in housework, childcare and sleep than women. Koreans spend the least time sleeping while Finns average the least time working and the most time in leisure activities. Australians have least leisure time, and conversely spend relatively large amounts of time in paid and unpaid work (men) and unpaid work (women). Spain has a broadly similar time profile to Australia, except that paid work is lower for men in the former than the latter country.

[Figure 1 about here]

\section{Multivariate regression results}

Results for the pooled (by country) and stratified (by gender) linear regressions confirmed that time in recuperative activities varied by country and that time in work activities varied by gender and country. Korean men did least unpaid work of men, and Finnish women did least unpaid work of women. Amongst men, Koreans work the longest hours, Australians next longest, and the Spanish and Finns work the shortest hours. Australian women average less work time than women in the other countries.

Our focus is how parenthood relates to these forms of time use. Figure 2 shows marginal effects on all five activities by gender, with the panels each illustrating contrasts by youngest child's age. Values above the zero line means parents do more than those without children and below the zero line means parents do less than those without children. The figure also indicates between country differences in the impact of parenthood and children's age for each gender, and we note statistically significant results below. 
[Figure 2 about here]

All men and women with young children under five years old were estimated to have less leisure than their childless compatriots (see top panel of Figure 2). Korean men reported the smallest difference which was significantly less than that found for Australian and Spanish men. Finnish fathers of 0-4-year-olds reported a difference of -98 minutes per day from Finnish non-fathers. This was significantly different to their Korean and Spanish, but not to their Australian, counterparts. For women there were no significant between-country differences. Thus, the leisure time gaps between nonparents and parents of 0-4-year-old children differed by country for men but not women.

The marginal differences in leisure between non-parents and parents of children aged 5-9 and 10-14 years were smaller (middle and lowest panels, Figure 2), showing the leisure penalty for parents of older children is less than that for parents of 0-4-year-olds. However, most parents still averaged significantly less leisure than childless people in the same country. The single exception is that Korean fathers of 5-9 or 10-14-year olds were estimated to have similar levels of leisure as their childless counterparts. Thus, when children are older, leisure time penalties were lower for all parents, but are especially so for Korean men.

We find narrower, but still telling, marginal differences in sleep. With a youngest child aged 0-4 years, Australian, Spanish and Finnish fathers reported less sleep than their childless peers. Korean fathers did not. Similarly, Australian, Spanish and Finnish mothers with youngest children aged 0-4 years reported significantly less sleep than women without children, but Korean mothers of children that age did not. The null results for Koreans may be related to the lower baseline for sleep time in that country (see Figure 1). The sleep difference with non-mothers reported by Australian mothers with a child aged 0-4 years was significantly more than that reported by Finnish, Spanish and Korean mothers. The sleep time of parents of older children generally equaled that of same-gender non-parents in the same country, with some exceptions. Australian mothers with a youngest child aged 5-9 years, and Australian and Korean mothers with a youngest child aged 10-14 years, were estimated to have less sleep than their childless counterparts. Finnish fathers with a youngest child aged 10-14 years reported less sleep than their childless peers.

We next examined how the productive activities of paid work, housework and childcare varied by parenthood status. In all countries, women with 0 -4-year-old children were estimated to do significantly less paid work than their childless peers (top panel Figure 2). Australian and Finnish mothers of children this age did significantly less than their counterparts in Korean and Spain. Negative associations between presence of children and maternal paid work with youngest children aged 5-9 years were found for Australian, Spanish and Korean mothers, but not for Finnish mothers. Australian mothers with a youngest child aged 10-14 years were also estimated to spend less time in paid work than Australian nonmothers. In contrast, Finnish mothers with a child aged 5-9 or 10-14 years were estimated to spend similar time in paid work as their childless compatriots, which is an important distinction between the countries. There was no significant association between parenthood and paid work for Korean, Spanish or Finnish men, indicating that in those countries, women cut back employment to accommodate parenthood, but men do not. Australian fathers with children 0-4 and Spanish fathers with 5-6-year-old children work significantly more than non-fathers.

In all the countries for both genders there were strong positive associations between childcare time and having children aged 0-4 years. All mothers of young children were also estimated 
to do more housework, as were equivalent Finnish fathers. Conversely, Korean and Spanish fathers of 0-4-year-olds were estimated to do less housework, and Australian fathers to do the same amount, as nonfathers. Mothers of older children were also estimated to spend longer in housework and childcare than their childless compatriots, although the marginal differences were attenuated. With 5-9-year-olds, the marginal effects were largest for Australian and Korean mothers. With children aged 10-14 Australian mothers were estimated to do more housework and childcare than their childless compatriots, a difference significantly $(\mathrm{p}<0.05)$ larger than that found for equivalent mothers elsewhere. All fathers of a youngest child aged 5-9 reported higher levels of unpaid work than their childless peers, with the marginal difference significantly smaller in Korea than in Australia and Finland. Finnish fathers of children aged 10-14 also reported higher levels of unpaid work than their childless peers while Korean fathers reported lower levels. Australian fathers do not differ from non-fathers.

Across all activities time changes in association with parenthood were larger for women than for men. Gender differences were widest in Korea and least in Finland. Korean men's time use differed relatively little by fatherhood, but in Australia fathers had substantially less leisure time and much higher unpaid work than childless men. Childless Finnish men enjoyed more recuperative time and less productive time than men in the other two countries, and fatherhood had the biggest effect on men's housework time in that country. Childless Australian and Korean women also had similar time profiles, but the associations with motherhood were larger for Australians. Finnish women experienced relatively large time impacts with young children, but the effects were markedly lower with older children. With adolescent children, mothers and fathers had similar time profiles in Finland. In the other countries gender contrasts remained wider.

To capture daily time constraint with younger and older children in each country, we show how time in each of the activities was scheduled over a typical weekday, for mothers and fathers with youngest children under 5 years old (Figure 3), and for mothers and fathers with youngest children aged 10-14 (Figure 4). It shows that in all countries, mothers are more temporally bound by unpaid work than fathers, but that with older children the gender differences are more evident in Australia than in the other countries.

[Figure 3 about here]

[Figure 4 about here]

Finally, we turn to logistic regression analysis to test associations between subjective time stress, and the presence and age of children in Australia, Korea and Finland (see Table 3).

In Australia, both men and women have significantly higher odds of being time pressured if they have children aged 0-4 (men 94\% and women 153\%) and if they have children aged 5-9 (men $81 \%$ and women 158\%). Australian women with children aged 10-14 also have significantly higher odds of being time pressured than childless women (86\%), but we did not find an equivalent association for Australian men.

\section{[Table 3 about here]}

In the other two countries, patterns were different both to Australia and to each other. Compared to their compatriots with no children, having children aged 0-4 or 5-9 years was associated with higher odds of Korean women being time stressed (121\% and 56\% respectively). For Korean men, only the presence of children aged 0-4 years was associated 
with significantly higher odds of time stress (31\%). Conversely, in Finland, fathers of children in the two youngest age groups were significantly more likely to report higher odds of being time stressed than non-fathers (228\% for age $0-4$ and $103 \%$ for age $5-9$ ), but there was no equivalent finding for women. Finnish mothers were no more likely to report time stress than Finnish non-mothers. Wald tests were used to compare the odds ratios for men and women for each age of the youngest child within each country. With youngest children aged 0-4 and aged 5-9, Korean mothers were significantly more likely to report subjective time pressure than Korean fathers $(\mathrm{p}<0.05)$. No gender differences were found in Australia and Finland.

\section{Discussion}

Motivated by the assumption that national policies, attitudes and practices could influence mothers and fathers' time tradeoffs and exacerbate or ameliorate the time pressure of parenthood, this chapter investigated how Australia compares with other countries in timerelated aspects of mothering. Australia, Spain, Korea and Finland have contrasting institutional features and social policy frameworks in relation to working time, gender equality, and cultural attitudes to parenting. As expected, we found cross-national contrast in how the recuperative activities of leisure and sleep, and the productive activities of paid work, housework and childcare were affected by parenthood, for each gender. In the main, feelings of time pressure broadly echoed objective time constraint. An exception was Finland, where objective and subjective time pressure slightly diverged, and did so differently for men and women. Overall our comparison confirmed that social conditions matter to how the work and time stress of parenthood falls by gender.

For example, time differences by fatherhood were remarkably limited for men in Korea. While Korean fathers of 0-4-year-olds reported somewhat less leisure and more unpaid work, and also had marginally higher odds of being subjectively time pressured, with older children their time allocation and time pressure was not different from that of their childless counterparts. It is likely pertinent that the marginal differences were from a baseline of relatively little sleep and long paid work hours for Korean men. A demanding work culture can constrain men's ability to contribute to the unpaid work of raising children (Dinh, Strazdins, and Welsh 2017). It may also be both cause and consequence of cultural gender attitudes that assign mothers responsibility for housework and family care (Budig, Misra, and Boeckmann 2012) and/or legitimize fathers claiming more leisure time than mothers (Mattingly and Bianchi 2003). In comparison, Korean women's time adjustments following parenthood were substantial. They involved multiple trade-offs between unpaid work, housework, leisure and sleep, the detail of which varied by children's age, but which were present for mothers of all age groups studied. The difference in how parenthood affects men and women in Korea is consistent with traditional gender attitudes, reported in Table 1, regarding who should provide care and who should prioritise paid work.

Finland is more progressive than the other countries in promoting gender equality and in emphasizing fathers', as well as mothers', involvement in family work (Gershuny and Sullivan 2003, Gornick and Meyers 2003). This study showed that, compared to men elsewhere, Finnish men experience relatively pronounced consequences, both in objective time allocation and in subjective time stress, of parenthood. This was not the case for Finnish women. With young children the marginal differences between mothers and non-mothers in time allocation were quite wide, as in the other countries. However, with older children, differences were much less. Importantly, the recuperative time penalties of motherhood were not present with older children. Also, in a rare instance of objective and subjective time 
pressure diverging, Finnish mothers did not differ from their childless counterparts in reported time stress.

The lack of a motherhood stress penalty could relate to Finnish women's relatively high baseline leisure and sleep time. Also, Finnish policy allows mothers to take maternity leave, and then access affordable childcare, and return to employment in a short-hours work time regime (Gornick and Meyers 2003). Finnish mothers' subjective time stress is possibly mitigated by the predictable and supportive institutional framework. Because Finnish fathers also enjoy comparatively high average leisure and low working hours, the finding that, unlike mothers, they do report time stress suggests that for them it is the marginal difference with Finnish non-fathers that is most pertinent. A possible reason for their significant subjective time pressure is that Finnish fathers share with Finnish mothers the responsibility for managing the work-family nexus.

A central aim of this chapter was to place Australian mothering in cross-national perspective. Australian patterns were most similar to Spain, which is recognised as being a highly conservative country with wide gender divisions of labour patterns (Gornick and Meyers 2003). However, findings revealed that the Australian context generated particularly high parenthood time penalties, both objective and subjective. Uniquely among the countries for which we had data, for women the time trade-offs and feelings of subjective time stress remained present with adolescent children, and mothers' paid work was less than nonmothers' across all three child age groups. This suggests the Australian policy environment and social norms are particularly inimical to new mothers taking a temporary work-break and then participating more fully in the workforce as children grow. In addition, their subjective time stress remained high. At the same time, Australian men's paid work hours were not reduced by fatherhood; rather, they went up. Also, father-non-father differences in unpaid work time, largely reflecting childcare time, were substantial. Australian fathers also had high odds of feeling time stressed, unsurprisingly given the additional childcare built on a comparatively high baseline amount of both paid and unpaid work. Overall the results suggest that, compared to Spain, Finland and Korea, Australian parenthood generates higher and more gendered workloads and lower leisure for both men and women, and also high stress for both genders.

\section{Conclusion}

Placing Australia in cross-national perspective has shown that compared with other countries, it generates particularly high parenthood time penalties that last longer into children lives than elsewhere. The patterns are related to the institutional context, so are unlikely to change without substantial public and workplace policy shifts. Learning from other countries' approach to work and family, notably the extensive supports available in Finland, could be prerequisite to mitigating the stress of motherhood and to promoting more gender-equal parenthood outcomes in Australia. Workplace regulation leading to shorter hours could free Australian fathers to participate more domestically, and formal services including cheaper, more accessible child- and after school- care could better facilitate Australian mothers' labour force attachment and earlier reentry into the workforce. 


\section{References}

Bianchi, Suzanne, and Melissa Milkie. 2010. "Work and family research in the first decade of the 21st Century." Journal of Marriage and Family no. 72 (3 ):705-725.

Bianchi, Suzanne, John Robinson, and Melissa Milkie. 2006. Changing rhythms of American family life. New York: Russell Sage.

Buddelmeyer, Hielke, Daniel S. Hamermesh, and Mark Wooden. 2017. "The stress cost of children on moms and dads "European Economic Review.

Budig, Michelle, and Paula England. 2001. "The wage penalty for motherhood." American Sociological Review no. 66:204-225.

Budig, Michelle, Joya Misra, and Irene Boeckmann. 2012. "The motherhood penalty in cross-national perspective: The importance of work-family policies and cultural attitudes." Social Politics no. 19 (2):163-193.

Craig, Lyn, and Killian Mullan. 2010. "Parenthood, gender and work-family time in USA, Australia, Italy, France and Denmark " Journal of Marriage and Family no. 72 (5):1344-1361.

Craig, Lyn, Brendan Churchill, and Melissa Wong. 2018. "Youth, Recession, and Downward Gender Convergence: Young People's Employment, Education, and Homemaking in Finland, Spain, Taiwan, and the United States 2000-2013." Social Politics: International Studies in Gender, State \& Society.

Dinh, Huong, Lyndall Strazdins, and Jennifer Welsh. 2017. "Hour-glass ceilings: Work-hour thresholds, gendered health inequities." Social l Science and Medicine no. 176:42-51.

Dribe, Martin, and Maria Stanfors. 2009. "Does parenthood strengthen a traditional household division of labor? evidence from Sweden." Journal of Marriage and Family no. 71 (1):33 45.

Gershuny, Jonathan, and Oriel Sullivan. 2003. "Time use, gender and public policy regimes." Social Politics no. 10 (2):205-228.

Gornick, Janet, and Marcia Meyers. 2003. Families that work: policies for reconciling parenthood and employment. New York: Russell Sage.

Hamermesh, Daniel, and Jungmin Lee. 2007. "Stressed out on four continents: time crunch or yuppie kvetch?" The Review of Economics and Statistics no. 89 (2):374-383.

Hurst, Matt. 2008. Who gets any sleep these days? Sleep patterns of Canadians. In Canadian Social Trends. Toronto: Statistics Canada.

Jacobs, Jerry, and Kathleen Gerson. 2004. The time divide: work, family, and gender inequality. Cambridge, Massachusetts: Harvard University Press.

Kleiner, Sibyl. 2014. "Subjective time pressure: general or domain specific?" Social Science Research no. 47 (1):108-120.

Lewis, Jane. 2009. Work-family balance, gender and policy. Cheltenham, UK, Northhampton, MA, USA: Edward Elgar.

Mattingly, Marybeth, and Suzanne Bianchi. 2003. "Gender differences in the quantity and quality of free time: The U.S. experience." Social Forces no. 81:999-1030.

Mattingly, Marybeth, and Liana Sayer. 2006. "Under pressure: Gender differences in the relationship between free time and feeling rushed." Journal of Marriage and the Family no. 68 (1):205221.

Monna, Berenice, and Anne Gauthier. 2008. "A review of the literature on the social and economic determinants of parental time " Journal of Family and Economic Issues no. 29 (4 ):634-653.

OECD. 2014. Lessons from PISA for Korea, strong performers and successful reformers in education. Paris: OECD Publishing.

Plage, Stephanie , Paco Perales, and Janeen Baxter. 2016. "Doing gender overnight? Parenthood, gender and sleep quantity and quality in Australia." Family Matters.

Rose, Judy, Belinda Hewitt, and Janeen Baxter. 2013. "Women and part-time employment Easing or squeezing time pressure?" Journal of Sociology no. 49 (1):41-59.

Sayer, Liana. 2016. "Trends in women’s and men’s time use, 1965-2012: back to the future?" Gender and Couple Relationships no. Volume 6 of the series National Symposium on Family Issues 43-77. 
Sayer, Liana, Anne Gauthier, and Frank Furstenberg. 2004. "Educational differences in parents' time with children: Cross-national variations." Journal of Marriage and Family no. 66 (5):11521169.

Strazdins, Lyndall, Amy Griffin, Dorothy Broom, Cathy Banwell, Rosemary Korda, Jane Dixon, Francesco Paolucci, and John Glover. 2011. "Time scarcity: another health inequality?" Environment and Planning no. 43:545-559.

Sullivan, Teresa. 2014. "Greedy institutions, overwork, and work-life balance." Sociological Inquiry no. 84 (1):1-15.

Waldfogel, Jane. 1998. "Understanding the "family gap" in pay for women with children." The Journal of Economic Perspectives no. 12 (1):137-156.

Yavorsky, Jill , Claire Kamp Dush, and Sarah Schoppe-Sullivan. 2015. "The production of inequality: the gender division of labor across the transition to parenthood." Journal of Marriage and Family no. 77 (3):662-679. 
Table 1: Features of institutional context in Australia, Korea, Spain and Finland

\begin{tabular}{|c|c|c|c|c|}
\hline & Australia & Korea & Spain & Finland \\
\hline \multicolumn{5}{|l|}{ Labour market } \\
\hline Male employment rates & 78 & 74 & 66 & 69 \\
\hline Men who usually work $40+$ hours & 72 & 87 & 71 & 58 \\
\hline Female employment rates & 66 & 52 & 53 & 68 \\
\hline Female part-time employment & 38 & 16 & 20 & 16 \\
\hline Gender wage gap in median fulltime earnings & 18 & 39 & 20 & 20 \\
\hline \multicolumn{5}{|l|}{ Attitudes: strongly agree/agree } \\
\hline Childcare: "when a woman works, children suffer" & 21 & 55 & 53 & 21 \\
\hline Work: "when jobs are scarce, men should have more right to a job than women" & 13 & 36 & 17 & 10 \\
\hline \multicolumn{5}{|l|}{ Education and childcare } \\
\hline Public expenditure formal childcare \% GDP & $\underline{0.6}$ & $\underline{0.7}$ & $\underline{0.6}$ & $\underline{1.1}$ \\
\hline Enrolment formal childcare/early education & & & & - \\
\hline Children $0-2$ years & $\underline{30}$ & $\underline{22}$ & $\underline{34}$ & $\underline{27}$ \\
\hline Children $3-5$ years & $\underline{66}$ & $\underline{91}$ & $\underline{97}$ & $\underline{74}$ \\
\hline$\underline{\text { Students attending after-school lessons \% }}$ & $\underline{12}$ & $\underline{66}$ & $\underline{40}$ & $\underline{7}$ \\
\hline Tertiary education rates $\%$ & $\underline{36.9}$ & $\underline{38.7}$ & $\underline{30.0}$ & $\underline{37.3}$ \\
\hline$\underline{\text { Total fertility rates }}$ & $\underline{2.0}$ & $\underline{1.2}$ & $\underline{1.3}$ & $\underline{1.9}$ \\
\hline
\end{tabular}

Sources OECD Family database. (http://www.oecd.org/els/soc/);World Values Survey 2010-2014 Waves 5 and 6 (http://www.worldvaluessurvey.org/wvs.jpp) 
Table 2: Descriptive statistics for Australia, Korea, Spain and Finland for household and individual variables

\begin{tabular}{|c|c|c|c|c|c|c|c|c|}
\hline & \multicolumn{2}{|c|}{ Australia } & \multicolumn{2}{|c|}{ Korea } & \multicolumn{2}{|c|}{ Spain } & \multicolumn{2}{|c|}{ Finland } \\
\hline Age of youngest child & \multicolumn{2}{|c|}{$\%$} & \multicolumn{2}{|c|}{$\%$} & \multicolumn{2}{|c|}{$\%$} & \multicolumn{2}{|c|}{$\%$} \\
\hline No children & \multicolumn{2}{|c|}{31.2} & \multicolumn{2}{|c|}{30.6} & \multicolumn{2}{|c|}{23.8} & \multicolumn{2}{|c|}{39.9} \\
\hline Aged 0-4 & \multicolumn{2}{|c|}{32.3} & \multicolumn{2}{|c|}{23.7} & \multicolumn{2}{|c|}{35.9} & \multicolumn{2}{|c|}{25.4} \\
\hline Aged 5-9 & \multicolumn{2}{|c|}{19.6} & \multicolumn{2}{|c|}{20.3} & \multicolumn{2}{|c|}{21.7} & \multicolumn{2}{|c|}{17.7} \\
\hline Aged 10-14 & \multicolumn{2}{|c|}{16.9} & \multicolumn{2}{|c|}{25.4} & \multicolumn{2}{|c|}{18.6} & \multicolumn{2}{|c|}{17.0} \\
\hline & M & $\mathrm{F}$ & M & $\mathrm{F}$ & $\mathrm{M}$ & $\mathrm{F}$ & M & $\mathrm{F}$ \\
\hline High subjective time stress & 64.3 & 66.3 & 38.2 & 31.4 & $\mathrm{n} / \mathrm{a}$ & $\mathrm{n} / \mathrm{a}$ & 22.7 & 22.5 \\
\hline Tertiary degree (\%) & 37.2 & 38.6 & 34.5 & 21.9 & 36.2 & 40.2 & 32.5 & 30.4 \\
\hline Age (mean[sd]) & $39.1[8.3]$ & $37.9[8.4]$ & $41.2[6.6]$ & $39.2[6.9]$ & $40.1[7.0]$ & $38.7[7.2]$ & $39.6[9.1]$ & $38.2[9.0]$ \\
\hline Number of persons & 1,090 & 1,241 & 2,987 & 3,161 & 2,420 & 2,666 & 587 & 661 \\
\hline
\end{tabular}


Table 3: Estimates for logistic regression models predicting subjective time stress for men and women in Australia, Korea and Finland

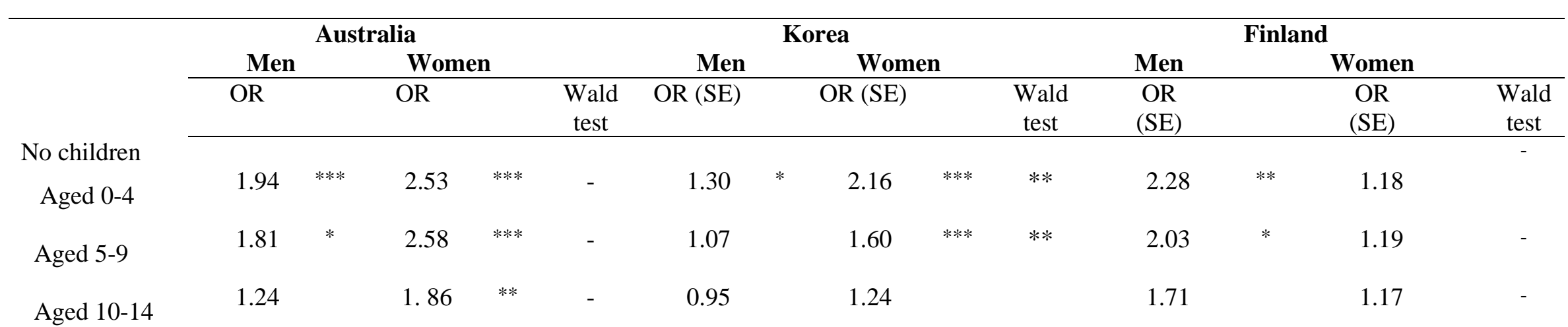

Notes: $* \mathrm{p}<0.05,{ }^{* *} \mathrm{p}<0.01,{ }^{* * *} \mathrm{p}<0.001$. Controlling for age, professional status, tertiary degree

Wald tests show significant within-country gender differences in time stress (only significant in Korea) 
Figure 1: Mean time spent in paid work, domestic work, childcare, leisure, and sleep, by men and women in Australia, Korea, Spain and Finland [minutes per weekday]

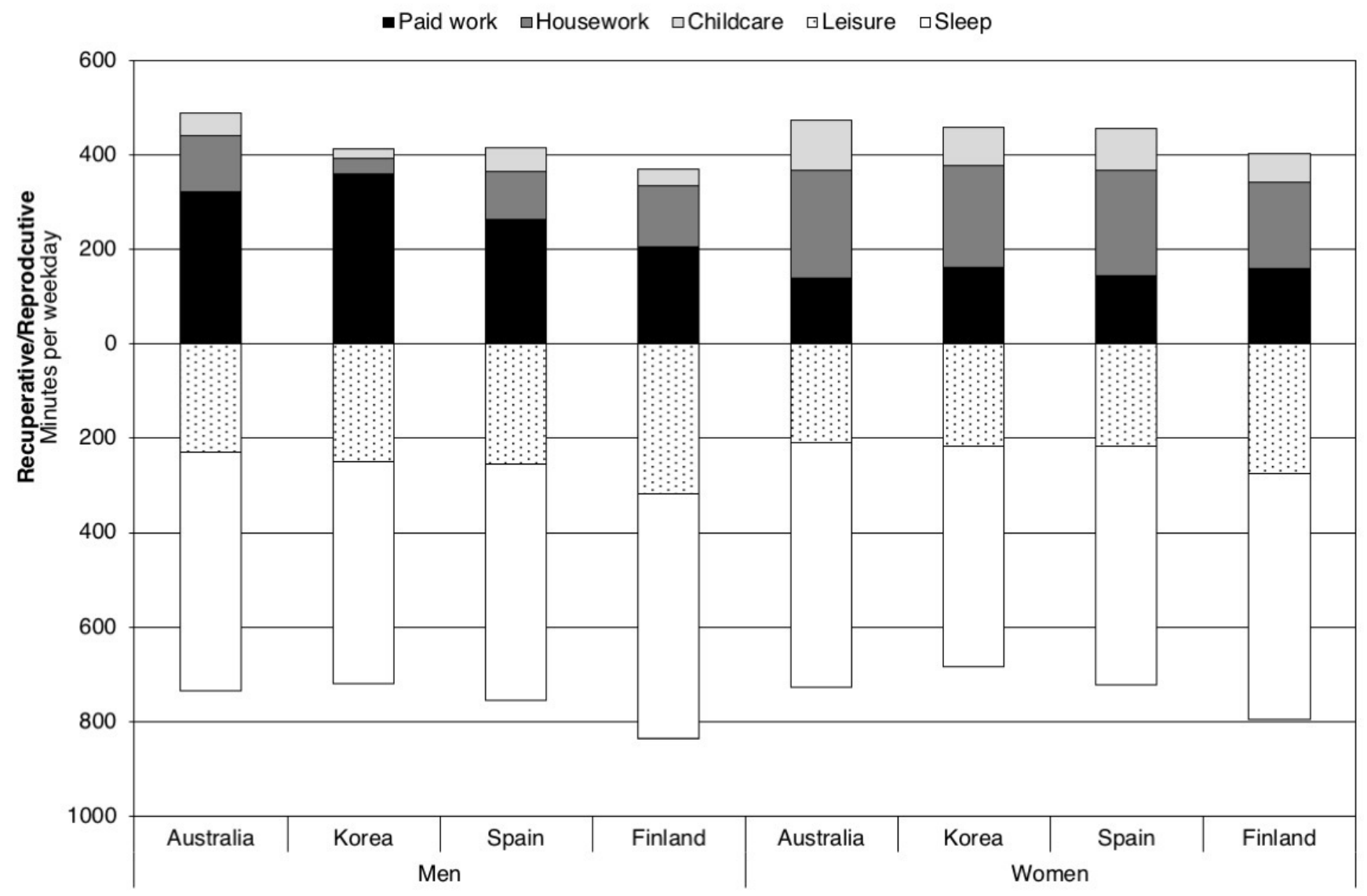


Figure 2: Marginal differences in time spent in leisure, sleep, paid work, housework and childcare by parents compared to non-parents in Australia, Korea, Spain and Finland
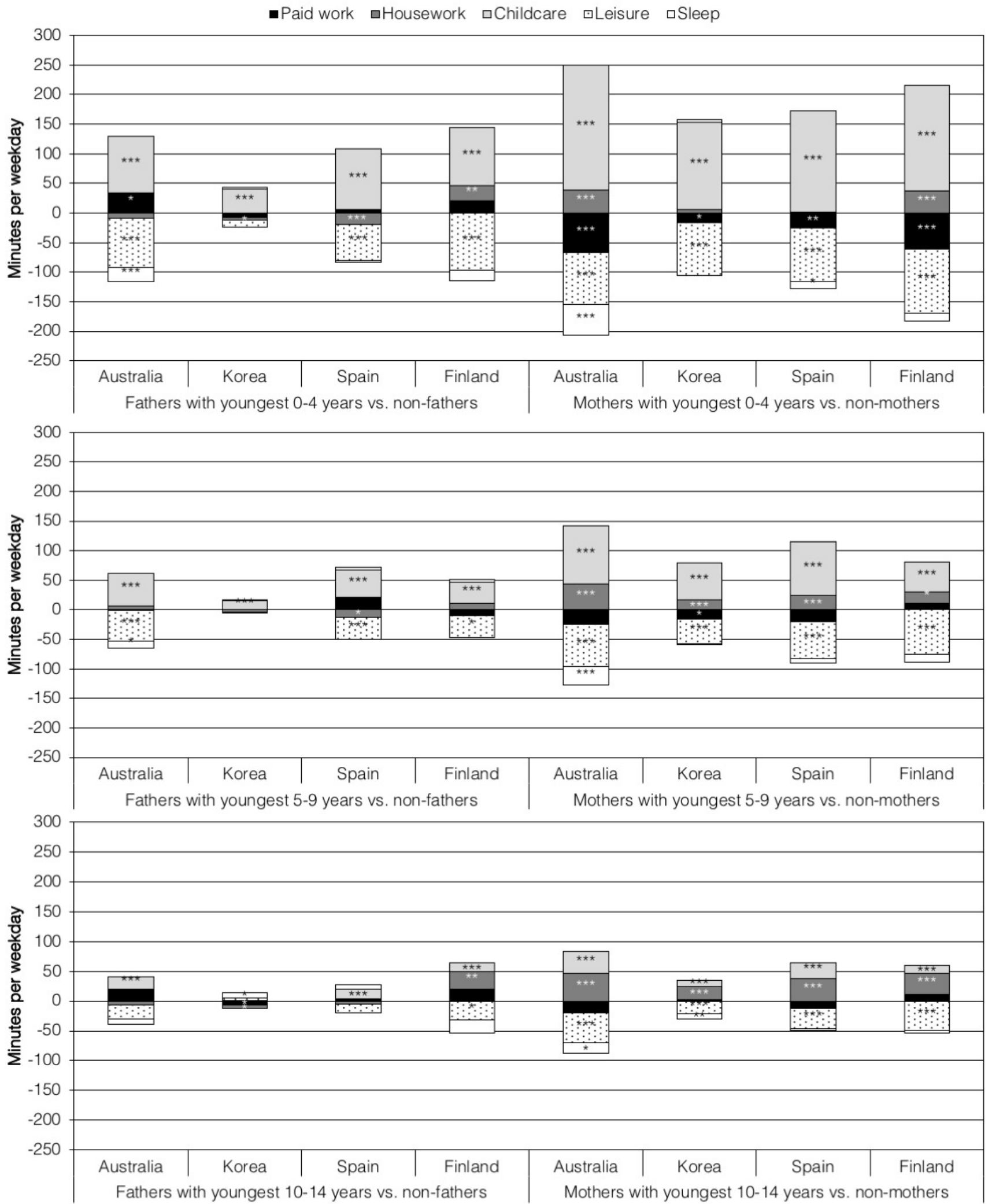

Controlling for age, professional status and college degree.

Comparions between fathers and non-fathers and mothers and non-mothers in each country.

Levels of significance: ${ }^{\star \star \star} \mathrm{P} \leq 0.001,{ }^{\star \star} \mathrm{P} \leq 0.01,{ }^{\star} \mathrm{P} \leq 0.05$ 
Figure 3. Tempogram of time spent in leisure, sleep, paid housework and childcare by parents with youngest child aged 0-4 in Australia, Korea, Spain and Finland

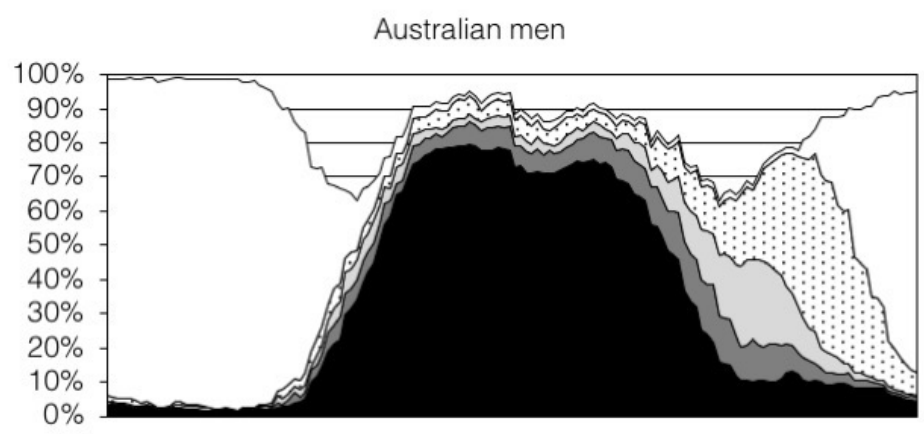

Korean men

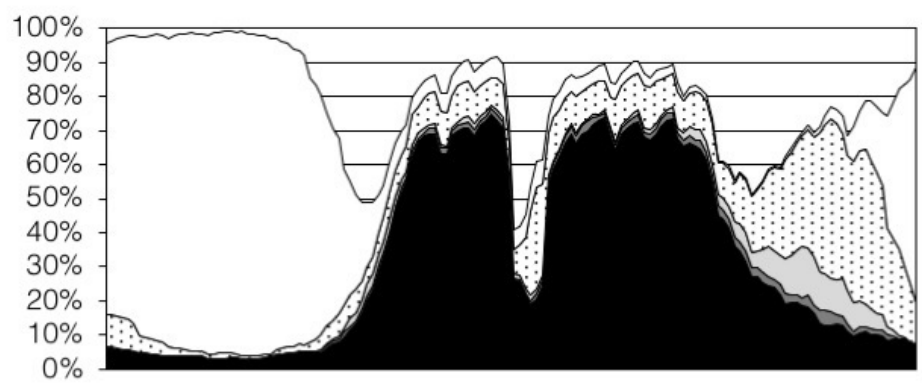

Spanish men

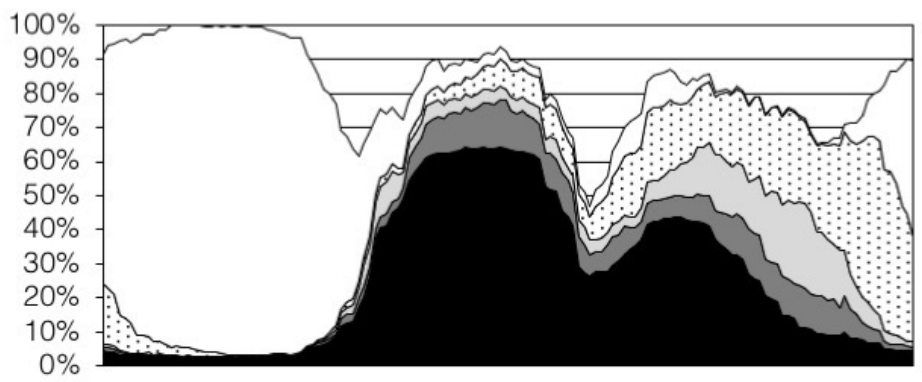

Finnish men

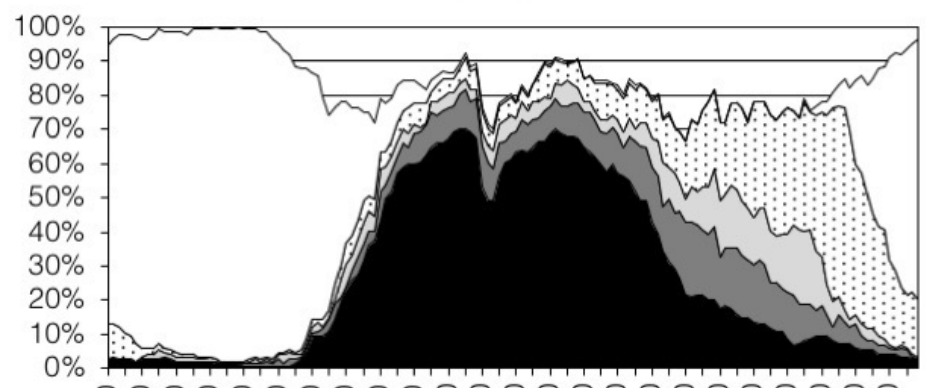

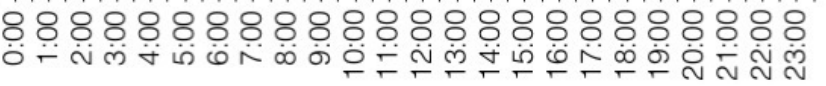

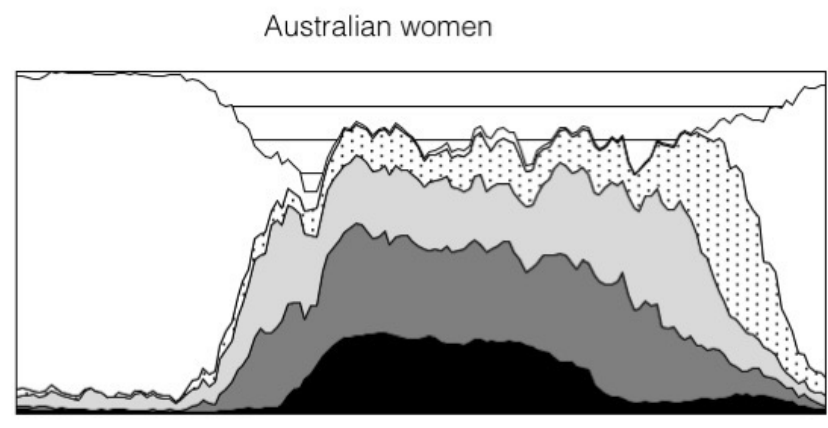

Korean women

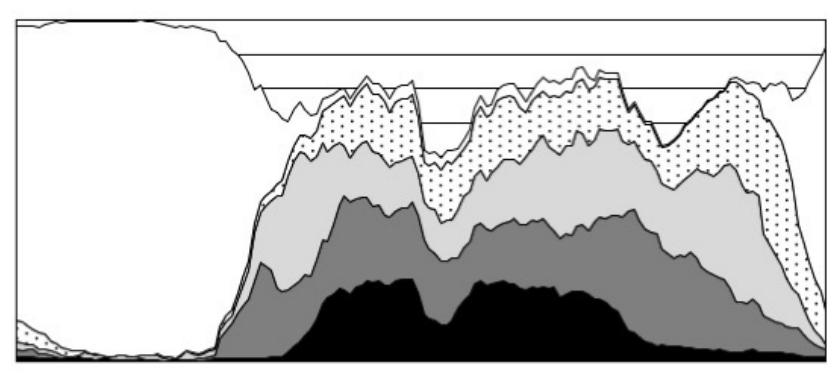

Spanish women

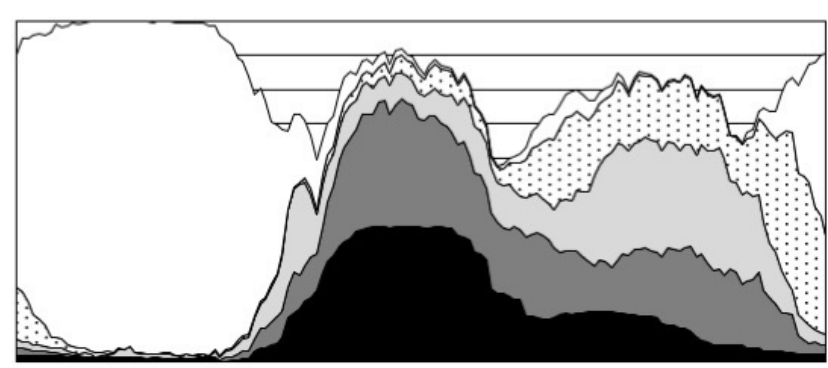

Finnish women

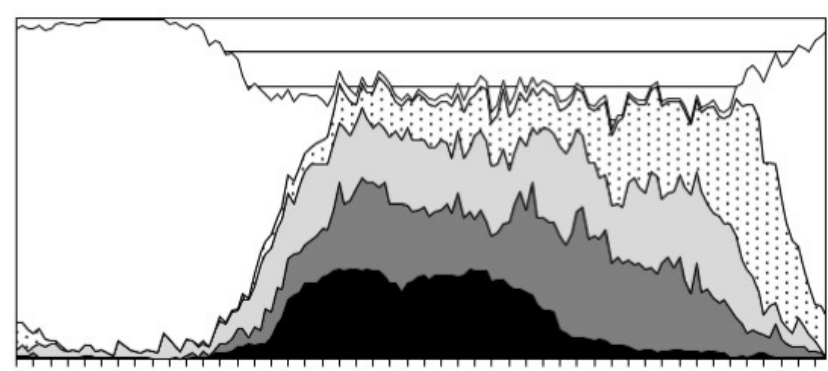

888888888888888888888880

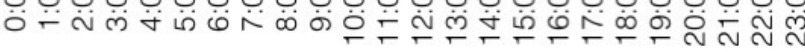
aPaidwork 口Housework $\square$ Childcare $\square$ Leisure $\square$ Sleep 
Figure 4. Tempogram of time spent in leisure, sleep, paid work, housework and childcare by parents with youngest child aged 10-14 in Australia, Korea, Spain and Finland

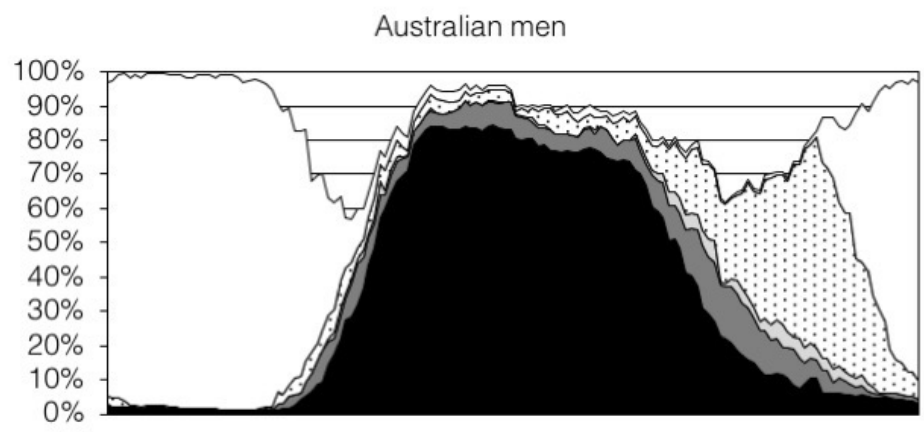

Korean men

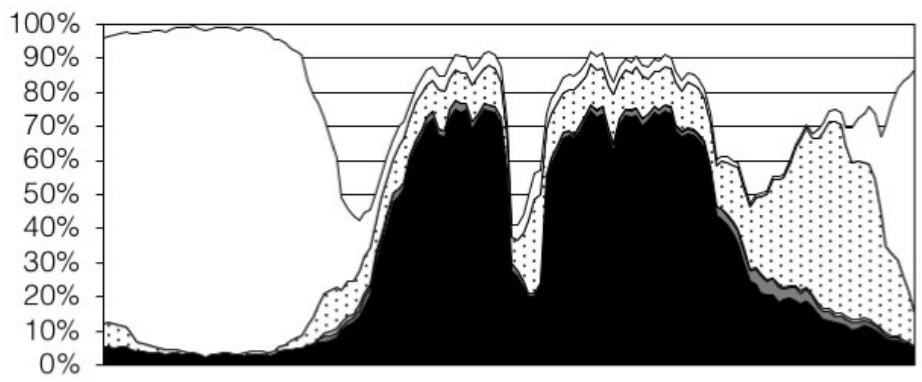

Spanish men

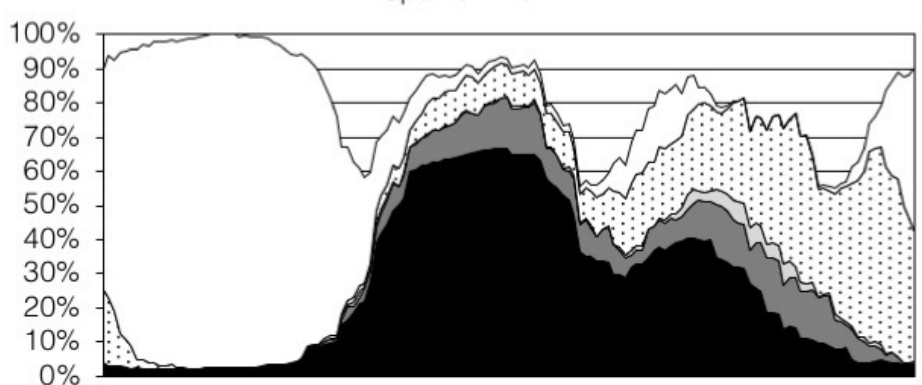

Finnish men

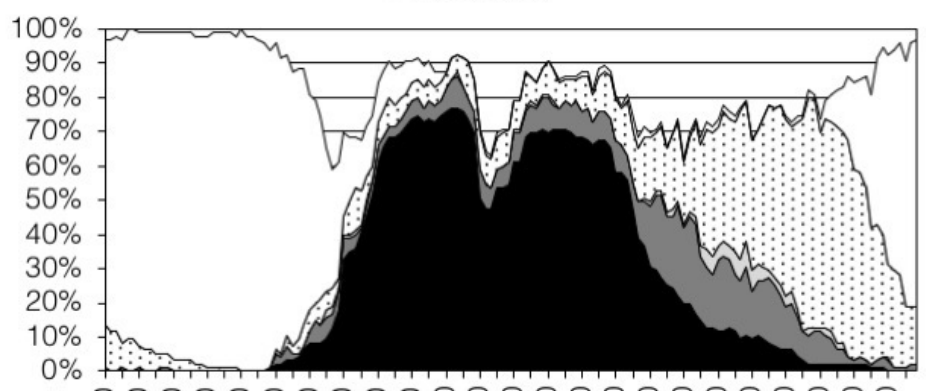

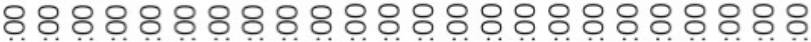
o-
Australian women

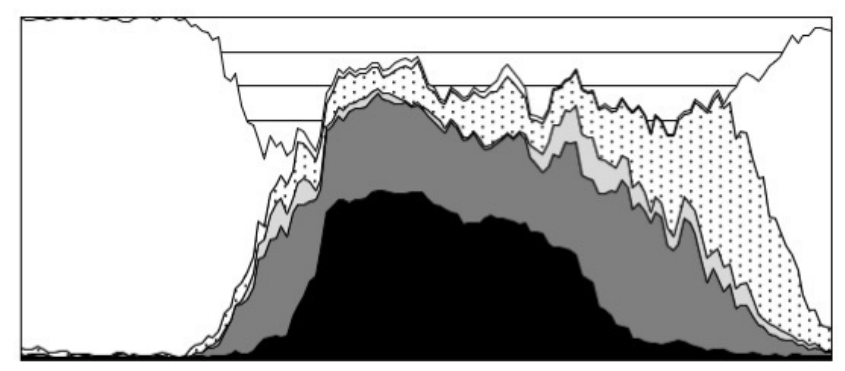

Korean women

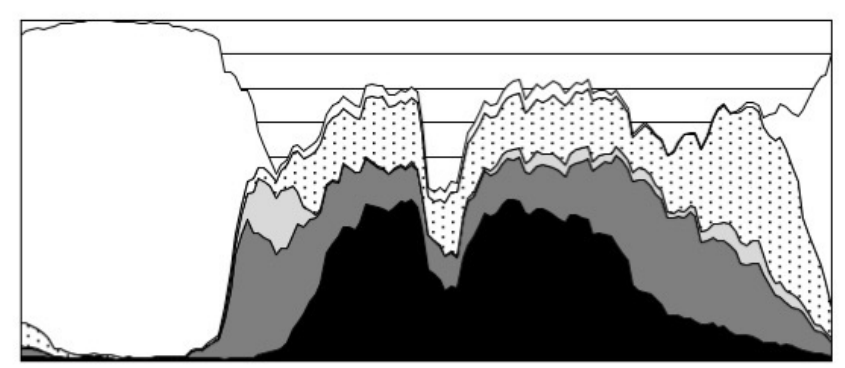

Spanish women

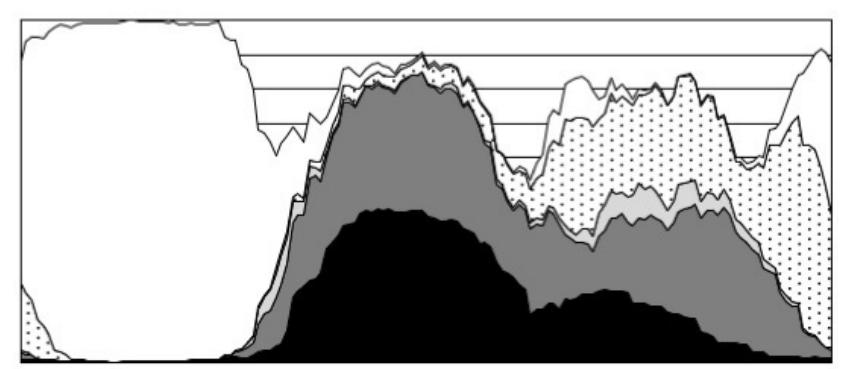

Finnish women

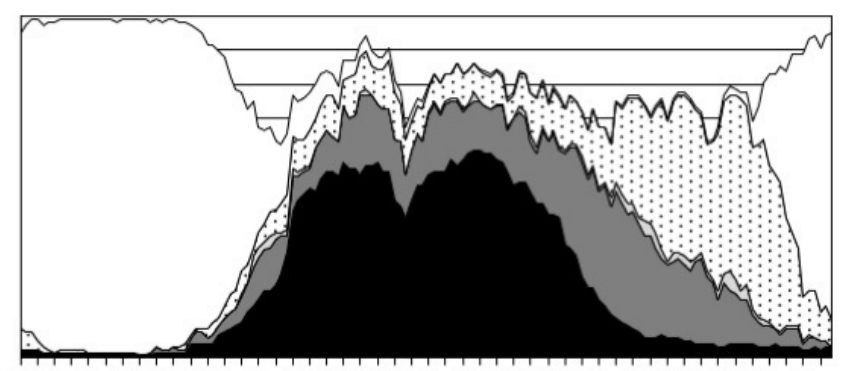

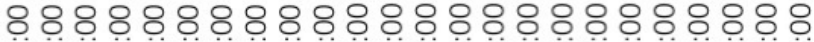

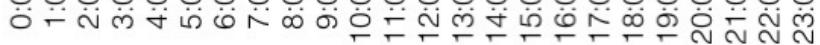
घPaid work $\square$ Housework $\square$ Childcare $\square$ Leisure $\square$ Sleep 


\section{University Library}

\section{- M M N E R VA A gateway to Melbourne's research publications}

Minerva Access is the Institutional Repository of The University of Melbourne

Author/s:

Craig, L;Brown, JE;Van Tienoven, TP

Title:

Australian mothering in cross-national perspective: Time allocation, gender gaps, scheduling and subjective time pressure

Date:

2019

Citation:

Craig, L., Brown, J. E. \& Van Tienoven, T. P. (2019). Australian mothering in cross-national perspective: Time allocation, gender gaps, scheduling and subjective time pressure. Leahy, C (Ed.). Bueskens, P (Ed.). Australian Mothering: Historical and Sociological Perspectives, (1), pp.317-336. Palgrave Macmillan.

Persistent Link:

http://hdl.handle.net/11343/251909 